\title{
Design buck converter with variable switching frequency by using matlab simulink simulation
}

\author{
Norazila Binti Md Posdzi ${ }^{1}$, Norsa'adah Binti Mahmor ${ }^{1}$, Rasidah Binti Abdul Rani ${ }^{1}$ \\ ${ }^{1}$ Department of Electrical Engineering, Politeknik Ungku Omar, Malaysia
}

\begin{tabular}{|c|c|}
\hline Article Info & ABSTRACT \\
\hline Article history: & This paper presents the design of a buck converter circuit with different input \\
\hline Received Sep 9th, 2020 & switching frequency by using Matlab Simulink software. This study focuses on \\
\hline Revised Oct 11th, 2020 & converter with 100VDC supply input, where the input switching frequency is \\
\hline Accepted Oct 25th, 2020 & use $5 \mathrm{kHz}$ and $25 \mathrm{kHz}$. This is because the input switching frequency of a buck \\
\hline & $\begin{array}{l}\text { converter affects many aspects of circuit functionality. This design of the circuit } \\
\text { used } 20 \% \text { of the duty cycle, and inductor value is } 25 \% \text { of Lmin to ensure the }\end{array}$ \\
\hline Keyword: & $\begin{array}{l}\text { operation is in continuous current mode. The evaluation of inductor current } \\
\text { and switching frequency used in the circuit and parameters for this analysis }\end{array}$ \\
\hline Buck Converter & based on the output voltage, inductor voltage and inductor current waveform. \\
\hline Switching Frequency & The design of the circuit verified by simulation and results compared with the \\
\hline Inductor Current & theoretical. In addition, the appropriate input switching frequency between \\
\hline MATLAB Simulink & $\begin{array}{l}5 \mathrm{kHz} \text { and } 25 \mathrm{kHz} \text { has been determined in order to use in the buck converter } \\
\text { circuit for } 100 \Omega \text { resistive load. }\end{array}$ \\
\hline
\end{tabular}

(C) 2020 The Authors. Published by IICET.

This is an open access article under the CC BY-NC-SA license

(https://creativecommons.org/licenses/by-nc-sa/4.0

\section{Corresponding Author:}

Norazila Binti Md Posdzi,

Department of Electrical Engineering, Politeknik Ungku Omar, Perak, Malaysia

Email: norazila.m@puo.edu.my

\section{Introduction}

The DC to DC converter is a static device that used to obtain a variable DC output voltage from a constant DC power supply (Hannon et al., 2007). It can be classified into two types is a buck converter and a boost converter. The DC converter widely used in many applications like for photovoltaic, battery supply in a laptop, computer, motor drives, trolling car, and communications (Lopa et al., 2016). A buck converter is the most popular application in the industry to convert a higher input DC voltage into a lower DC output voltage (Espacios et al., 2019). The average output voltage is changed by changing the during time switched on which output voltage is connected to the input. This conversion process can be achieved with a combination of an inductor, capacitor, semiconductor switching devices in a high-frequency switching mode (Xiao et al., 2017).

This paper is study focuses on the design of a buck converter with a different input switching frequency by using fixed a resistive load. Most of buck converter circuit is designing with continuous current mode operation. Due to choice, the best switching frequency can depend on the value of the inductor and capacitor. The switching frequency of a DC converter affects many aspects of circuit functionality The trade-off for 
higher switching frequency, audio noise is more comfortable to control and should be adjusted according to the requirement of the system (Robert, 2018).

In design the buck converter circuit, several parameters can be followed, such as switching frequency, duty cycle, inductance and capacitor values, output voltage ripple, inductor current and output voltage. The purpose of this study is to verify by simulation and the results are compared with the theoretical of output voltage, inductor current and an inductor voltage waveform of the circuit. It can determine the suitable switching frequency for the buck converter circuit.

\section{Operation of Buck Converter Circuit}

In design and build the buck converter circuit, the analysis is beginning by making this assumption the circuit is operating in the steady-state, the inductor current is continuous current mode operation and the output voltage is kept constant at voltage Vo (Rashid,2017).

Buck converter circuit is known as a step-down converter because the output voltage is less than the input voltage. The circuit diagram of a buck converter shown in Figure 1.

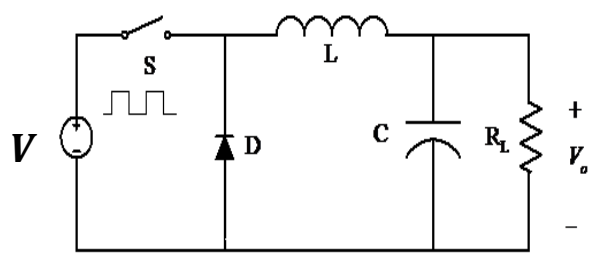

Figure $1<$ Buck Converter Circuit $>$

The operation of buck converter can divide into two modes, mode 1 when switch closed and mode 2 when switch opened. A BJT, MOSFET or IGBT can implement the switch. When the switch is closed, the current will flow from the DC supply, Vs through inductor and resistor load, as shown in Figure 2(a). The current through the inductor increase and the energy stored in the inductor increase until the switch is turned off (Gupta et al., 2014). At this time, the diode is reversed bias and blocking the path for current, so it produces $\mathbf{V}_{\mathbf{L}}$ $=$ VS - Vo.

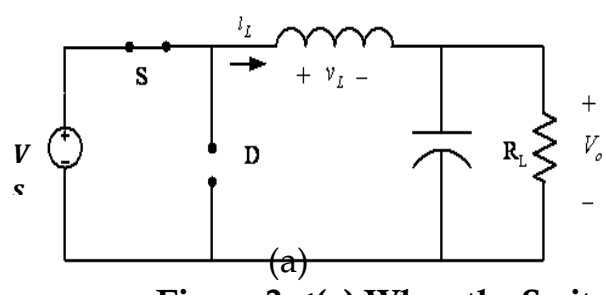

Figure $2<$ (a) When the Switch is Closed,

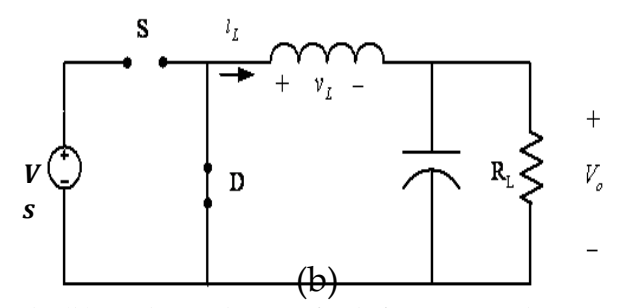

(b) When the Switch is Opened>

When the switch is opened, the diode becomes forward biased and the inductor act as a source to maintains the current flows to a resistor load, as shown in Figure 2 (b). The purpose of the diode is to provide a path for the load current when the switch is opened. The current will flow from the inductor, resistor load and diode so it produces $\mathbf{V}_{\mathbf{L}}=-$ Vo. The energy stored in the inductor decreases and its current falls until switched on again in the next cycle (Gupta et al., 2014).

The voltage output $\mathrm{Vo}$ is, $\mathrm{Vo}=\mathrm{Vs} \mathrm{D}$

--- Equation 1

In the steady-state operation, the average capacitor current must be zero, so the average inductor current is the same as the average current in the load resistor,

$$
I_{L}=I o=\frac{V o}{R} \quad \text {--- Equation } 2
$$

The inductor current can be discontinuous or continuous mode depending on the values of the inductor, capacitor and switching frequency (Izwan, 2013). If the continuous current mode operation, the inductor current is considered to differ between minimum inductor current, $I_{\min }$ and maximum inductor current, $I_{\max }$ and that the inductor current increases and decreases linearly (Rashid,2017). The inductor voltage, inductor 
current and output voltage waveforms as shown in Figure 3. The minimum and maximum values of the inductor current are computed as

$$
I_{\min }=V o\left(\frac{1}{R}-\frac{1-D}{2 L f}\right) \quad \text { and } \quad I_{\max }=V o\left(\frac{1}{R}+\frac{1-D}{2 L f}\right) \quad \text {--- Equation } 3
$$

By using Eqs 6, peak to peak inductor current ripple is, $\Delta i L=I_{\max }-I_{\min }$. If the desired switching frequency is established, the minimum inductance, $\mathrm{L}_{\min }$ is required for the continuous current mode. In practice, a value of inductance higher than $L_{\min }$ is desirable to ensure continuous current. Some designers select the value of the inductor is 25 percent to 40 percent larger than $L_{\min }$ (Rashid,2017).

$$
L \min =\frac{(1-D) R}{2 f} \text { for continuous current, } I_{\min } \geq 0 \quad \text {--- Equation } 4
$$

From the analysis for output voltage ripple, the capacitor is considered very large to ensure the output voltage is constant (Rashid,2017). In design, an equation to express required capacitance in terms of specified voltage ripple is

$$
C=\frac{1-D}{8 L(\Delta V o / V o) f^{2}} \quad \text {--- Equation } 5
$$

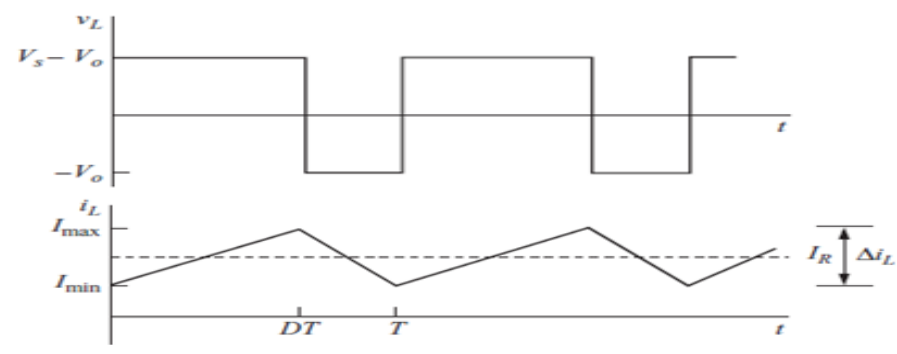

(a)

(b)

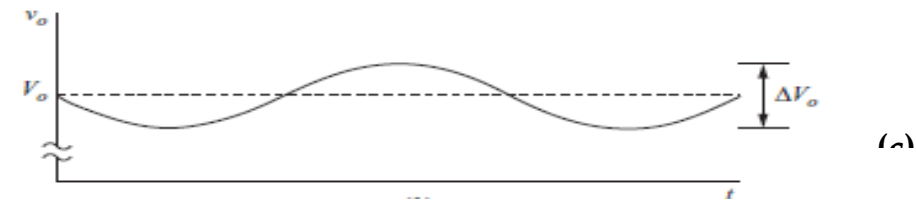

Figure 3 <Buck Converter Waveform (a) Inductor Voltage (VL), (b) Inductor Current (IL) and (c) Output Voltage (Vo)>

\section{Design Buck Converter Circuit}

A buck converter can be designed and a good design makes high performances of the circuit. In the first stage of design, we present the operation of the buck converter circuit. Then we calculate the values of the inductor and capacitor based on the different switching frequency $5 \mathrm{kHz}$ and $25 \mathrm{kHz}$. In the third stage, from the value of an inductor, capacitor, a resistor obtained from the analysis, the buck converter circuit is designing using MATLAB Simulink software. Finally, in the fourth stage, the results and discussion of the differences between simulations and theories are presented.

For the starting the study, the buck converter circuit is designed with switching frequency $5 \mathrm{kHz}$, the input voltage is $100 \mathrm{~V}$, the duty cycle is $20 \%$ operation, and with a fixed $100 \Omega$ resistive load. The minimum inductor size is determined to obtain the value of the inductor because the value of the inductor should be more significant than $\mathrm{L}_{\min }$ to ensure the operation of the circuit is the continuous current mode (Rashid, 2017). The minimum inductor size is determined by using Equation 4.

$$
L_{\min }=\frac{(1-D) R}{2 f}=\frac{(1-0.2) 100}{2(5000)}=\underline{\underline{8 m H}}
$$

The design used a value of inductance is $25 \%$ larger than $\mathrm{L}_{\min }$.

$$
L=\left(\frac{25}{100} \times \mathrm{L}_{\min }\right)+\mathrm{L}_{\min }=(0.25 \times 8 \mathrm{mH})+8 \mathrm{mH}=\underline{\underline{10 \mathrm{mH}}}
$$


To provide a peak to peak inductor current in continuous mode using Equation 2,

$$
I_{L}=I_{O}=\frac{V o}{R}=\frac{20}{100}=\underline{\underline{0.2 A}}
$$

The maximum and minimum values of the inductor current are determined by using Equation 3 :

$$
\begin{array}{ccc}
I_{\max }=20\left(\frac{1}{100}+\frac{1-0.2}{2 \times 10 \mathrm{~m} \times 5000}\right) & ; & I_{\min }=20\left(\frac{1}{100}-\frac{1-0.2}{2 \times 10 \mathrm{~m} \times 5000}\right) \\
=20(0.01+0.008)=\underline{\underline{0.36 \mathrm{~A}}} & =20(0.01-0.008)=\underline{\underline{0.04 \mathrm{~A}}}
\end{array}
$$

In design, it is used the output voltage ripple must not exceed 1 percent. Since the output voltage ripple is small, a constant output voltage was reasonable. The value of the capacitor is selected by using Equation 5;

$$
C=\frac{1-0.2}{8 \times 10 \mathrm{mH} \times(1 / 100) \times(5000)^{2}}=\underline{\underline{40 \mu F}}
$$

Then, buck converter circuit is designed with switching frequency $25 \mathrm{kHz}$ with the same voltage output is $100 \mathrm{~V}$, the duty cycle is $20 \%$ operation, the output voltage is $20 \mathrm{~V}$, the inductor current is $0.2 \mathrm{~A}$ and $100 \Omega$ resistive load. The minimum inductor size is determined,

$$
L_{\min }=\frac{(1-D) R}{2 f}=\frac{(1-0.2) 100}{2(25000)}=\underline{\underline{1.6 m H}}
$$

The design used a value of inductance is $25 \%$ larger than $\mathrm{L}_{\text {min }}$.

$$
L=\left(\frac{25}{100} \times \mathrm{L}_{\text {min }}\right)+\mathrm{L}_{\min }=(0.25 \times 1.6 \mathrm{mH})+1.6 \mathrm{mH}=\underline{\underline{2 \mathrm{mH}}}
$$

Maximum and minimum values and peak to peak of inductor current with switching frequency $25 \mathrm{kHz}$ is equal to $5 \mathrm{kHz}$ because the change of switching frequency value does not affect in inductor current, $\mathrm{I}_{\mathrm{L}}$ and output current, Io. Last, in design the circuit it is used the output voltage ripple must not exceed 1 percent to find the value of a capacitor by using Equation 5.

$$
C=\frac{1-0.2}{8 \times 2 \mathrm{mH} \times(1 / 100) \times(25000)^{2}}=\underline{\underline{8 \mu F}}
$$

\section{Result and Discussion}

In the first step, the buck converter was designed with switching frequency $5 \mathrm{kH}$, resistive load is $100 \Omega$ and IGBT as a switching device by using MATLAB Simulink as in Figure 4. From the calculation, the value of inductor is $10 \mathrm{mH}$ and a capacitor is $80 \mathrm{uF}$.

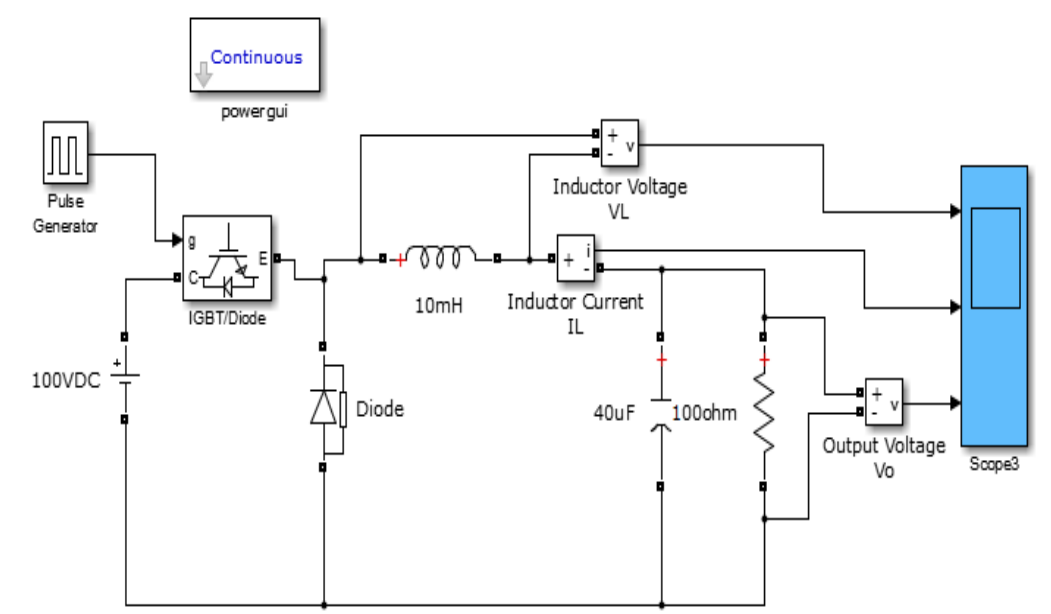

Figure 4 <Buck Converter Circuit with $5 \mathrm{KHz}$ Switching Frequency> 


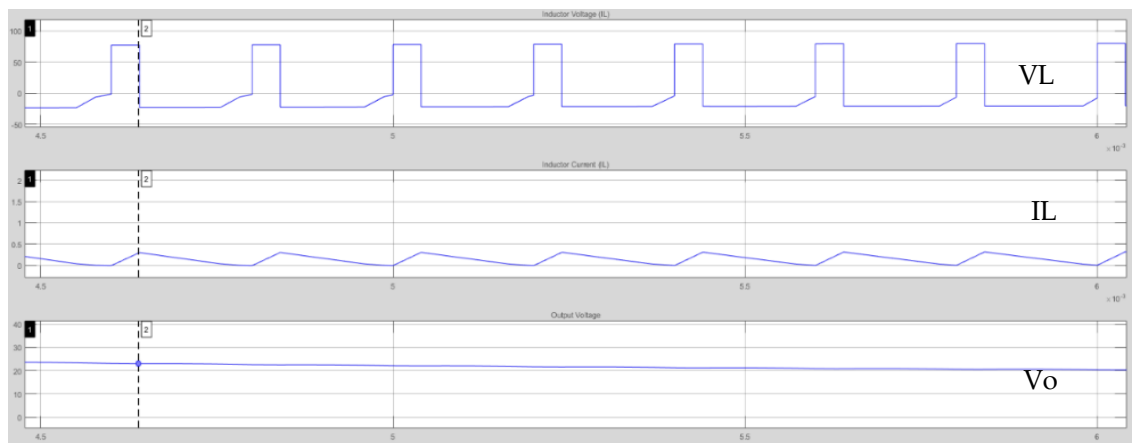

Figure \#5 Buck converter waveform for Inductor voltage (VL), Inductor current (IL) and Output Voltage (Vo)

Table $1<$ Comparison the Parameter between Calculation and Simulation>

\begin{tabular}{lcccc}
\hline Parameter & Calculation & Simulation & Relative Error & Accuracy \\
\hline $\mathbf{V L}_{\mathbf{O N}}$ & $80 \mathrm{~V}$ & $79.75 \mathrm{~V}$ & 0.0031 & 0.9969 \\
$\mathbf{V L}_{\text {OFF }}$ & $-20 \mathrm{~V}$ & $-23.589 \mathrm{~V}$ & 0.179 & 0.821 \\
$\mathbf{I L}$ & $0.2 \mathrm{~A}$ & $0.14 \mathrm{~A}$ & 0.3 & 0.7 \\
$\Delta \mathbf{I L}$ & $0.32 \mathrm{~A}$ & $0.327 \mathrm{~A}$ & 0.022 & 0.978 \\
$\mathbf{I}_{\max }$ & $0.36 \mathrm{~A}$ & $0.316 \mathrm{~A}$ & 0.122 & 0.878 \\
$\mathbf{I}_{\min }$ & $0.04 \mathrm{~A}$ & $-0.01 \mathrm{~A}$ & 1.25 & 0.25 \\
$\mathbf{V o}$ & $20 \mathrm{~V}$ & $21.647 \mathrm{~V}$ & 0.082 & 0.918 \\
$\Delta \mathbf{V o} / \mathbf{V o}$ & $1 \%$ & $15.01 \%$ & 14.01 & 13.01 \\
\hline
\end{tabular}

Based on Table 1, the accuracy for all result is nearest to 1 expect the reading for $\mathrm{IL}$ and $\Delta \mathrm{Vo} / \mathrm{Vo}$. This happens because the switching frequency is below $20 \mathrm{KHz}$. When the switching frequency below $20 \mathrm{Khz}$, the audio noise was appearing (Rashid,2017). By referring to output voltage ripple from the simulation result, the low-frequency oscillation is natural to occur when the switching frequency is low. This was happening because the switching frequency is affected by low-frequency oscillation (Wang et al., 2011). The buck converter waveform for inductor voltage, inductor current, and output voltage, as shown in Figure 5.

In the second step, the buck converter was designed with switching frequency $25 \mathrm{kH}$, resistive load is $100 \Omega$ and IGBT as a switching device by using MATLAB Simulink. From the calculation, the value of inductor is $2 \mathrm{mH}$ and a capacitor is $8 \mathrm{uF}$.

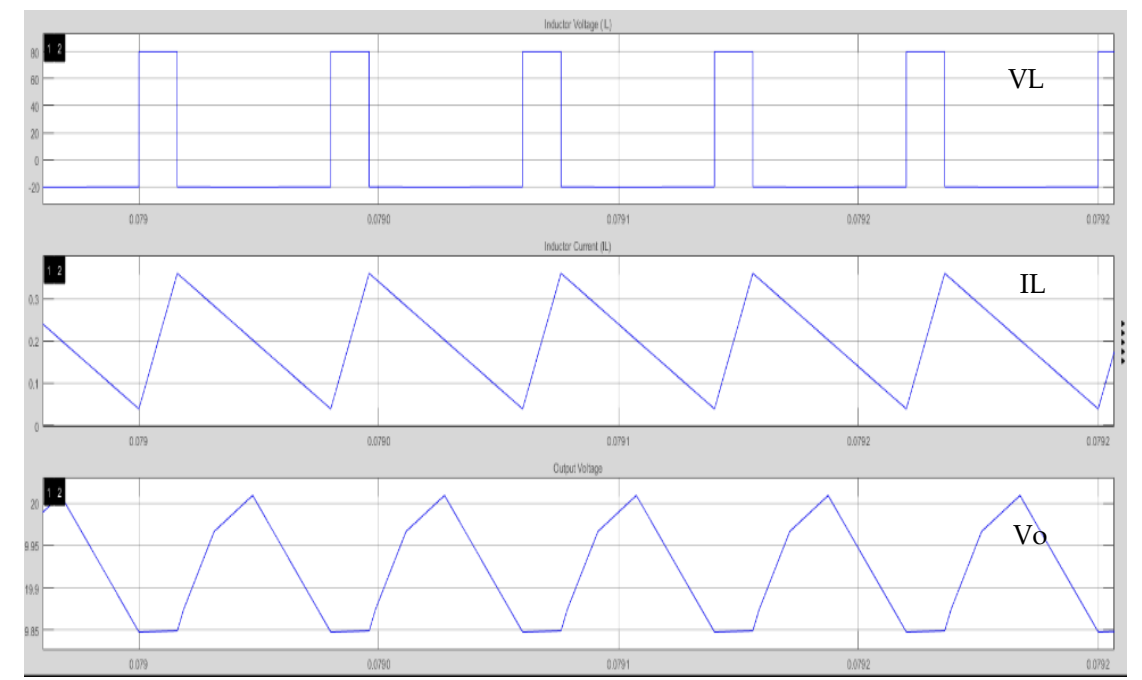

Figure \#7 Buck converter waveform for Inductor voltage (VL), Inductor current (IL) and Output Voltage (Vo) 
Table $2<$ Comparison the Parameter between Calculation and Simulation>

Based on Table 2, the accuracy for all result is nearest to 1 means simulation result is the same with the

\begin{tabular}{lcccc}
\hline Parameter & Calculation & Simulation & Relative Error & Accuracy \\
\hline $\mathbf{V L}_{\text {ON }}$ & $80 \mathrm{~V}$ & $80.132 \mathrm{~V}$ & 0.0017 & 0.9983 \\
$\mathbf{V L}_{\text {OFF }}$ & $-20 \mathrm{~V}$ & $-20.089 \mathrm{~V}$ & 0.00445 & 0.99555 \\
$\mathbf{I L}$ & $0.2 \mathrm{~A}$ & $0.221 \mathrm{~A}$ & 0.105 & 0.895 \\
$\Delta \mathbf{I L}$ & $0.32 \mathrm{~A}$ & $0.32 \mathrm{~A}$ & 0 & 1 \\
$\mathbf{I}_{\max }$ & $0.36 \mathrm{~A}$ & $0.356 \mathrm{~A}$ & 0.011 & 0.999 \\
$\mathbf{I}_{\min }$ & $0.04 \mathrm{~A}$ & $0.039 \mathrm{~A}$ & 0.025 & 0.975 \\
$\mathbf{V o}$ & $20 \mathrm{~V}$ & $19.893 \mathrm{~V}$ & 0.00535 & 0.99465 \\
$\Delta$ Vo/ & $1 \%$ & $0.8 \%$ & 0.2 & 0.8 \\
\hline
\end{tabular}

calculation. This happens because the switching frequency is used $25 \mathrm{kHz}$. Besides, the buck converter waveform for inductor voltage, inductor current and output voltage, as shown in Figure 5 same with the buck converter waveform as a theory in Figure 3.

\section{Conclusion}

Based on the buck converter circuit design, the influence of switching frequency on the output voltage ripple is analyzed in this paper. The simulation results described that the switching frequency could be effected to the output voltage ripple in the buck converter circuit, in which the $5 \mathrm{kHz}$ switching frequency is not suitable to use for the buck converter circuit by using IGBT as a switch. If using higher frequencies, the voltage output ripple is lower (Robert,2018). The most suitable value for this design circuit is used the switching frequency more than $20 \mathrm{kHz}$ to avoid the noise occur during the switching process (Rashid, 2017). Besides that, the higher switching frequencies can have affected the value of the inductor and capacitor (Xie et al., 2019). The lower value of the inductor makes the better continuous current mode operation, and the lower value of the capacitor can reduce the ripple at the output voltage. Finally, the switching frequency above $20 \mathrm{kHz}$ suitable to use in design the buck converter circuit for $100 \Omega$ resistive load.

\section{References}

Espacios, H. R., \& Autores, L. O. S. (2019). Methodology for teaching the buck converter: step by step description of the design. (2005).

Gupta, M., \& S. P. Phulambrikar. (2014). Design and Analysis of Buck Converter. 3(3), 2346-2350

Izwan. (2013). Buck Converter Switching Design Using Microcontroller. Universiti Tun Hussein Onn Malaysia.

Lopa, S. A., Hossain, S., Hasan, M. K., \& Chakraborty, T. K. (2016). Design and Simulation of DC-DC Converters. International Research Journal of Engineering and Technology, 2395-56.

Rashid, Muhammad (2017), Power Electronic Handbook (4t Edition). San Diego, California: Academic Press.

Robert (2018), How to Choose the Frequency of Your Switching Regulator, Retrieved from

https://www.allaboutcircuits.com/technical-articles/how-to-choose-the-frequency-of-your-switchingregulator/

S.A. Ali, N.A. Riyard, Design of a Non-Ideal Buck Converter Volume 03 Issue 2. International Research Journal of Engineering and Technology.

Wang, F., \& Ma, X. (2011). Research on the influence of switching frequency on low-frequency oscillation in the voltage-controlled buck-boost converter. Mathematical Problems in Engineering, 2011. https://doi.org/10.1155/2011/926403

Xiao, Z., Khoa, B. a., \& Siek, L. (2017). On-chip reconfigurable switched-capacitor DC-DC converter for indoor PV energy harvesting. Electronics Letters, 53(2), 108-110. http://doi.org/10.1049/el.2016.3018

Xie, H., \& Guo, E. (2019). How the Switching Frequency Affects the Performance of a Buck Converter. 1-8. 